\title{
The South African child death review pilot: A multiagency approach to strengthen healthcare and protection for children
}

S Mathews, ${ }^{1}$ MPH, PhD; L J Martin, ${ }^{2}$ MB BCh, Dip For Med (SA), MMed Path (Forens); D Coetzee, ${ }^{3}$ BA, MB BCh, DTM\&H, FCPHM (SA), MS (Epi); C Scott, ${ }^{4}$ MB ChB, FC Paed (SA); T Naidoo, ${ }^{5,6}$ MB ChB, Dip For Med (SA), LLM MDL, FC For Path (SA); Y Brijmohun, ${ }^{5,6}$ MB ChB, FC For Path (SA); K Quarrie, ${ }^{5}$ MB ChB, Dip For Path (SA), FC For Path (SA), MMed

${ }^{1}$ Children's Institute, Faculty of Health Sciences, University of Cape Town, South Africa

${ }^{2}$ Division of Forensic Medicine and Toxicology, Faculty of Health Sciences, University of Cape Town, South Africa

${ }^{3}$ Health Impact Assessment, Western Cape Department of Health, Cape Town; and School of Public Health and Family Medicine, Faculty of Health Sciences, University of Cape Town, South Africa

${ }^{4}$ Department of Paediatrics and Child Health, Faculty of Health Sciences, University of Cape Town, South Africa

${ }^{5}$ Forensic Pathology Services, KwaZulu-Natal Department of Health, Durban, South Africa

${ }^{6}$ Department of Forensic Medicine, School of Laboratory Medicine and Medical Sciences, College of Health Sciences, Nelson R Mandela School of Medicine, University of KwaZulu-Natal, Durban, South Africa

Corresponding author:S Mathews (shanaaz.mathews@uct.ac.za)

Background. Child mortality trends in South Africa (SA) show a decrease, but remain high and appear to have plateaued. To attain the new sustainable development goals, we need a better understanding of causes of death and the associated factors.

Objectives. To describe the SA child death review (CDR) pilot, the pattern of child deaths reviewed and the factors associated with these deaths. Methods. CDR teams were established at two pilot sites, Salt River mortuary (Western Cape Province) and Phoenix mortuary (KwaZulu-Natal Province). All child deaths were reviewed by a multidisciplinary team at the pilot sites for the period 1 January 2014 - 31 December 2014. Results. The CDR pilot reviewed 711 cases. Over half (53.3\%) were natural deaths, as opposed to $42.6 \%$ non-natural deaths. Most infant deaths (83.9\%) were due to natural causes, while $91.7 \%$ of deaths in the $15-17$-year-old age group were due to injuries. The leading cause of deaths reviewed (30.8\%) was respiratory tract infection (RTI), mainly among infants (51.6\%). Homicide was the second most common cause of death and affected children of all ages, with the highest burden (52.8\%) in the 15 - 17-year age group. Child abuse and neglect accounted for $11.3 \%$ of deaths. RTI was shown to be more likely after the neonatal period (odds ratio (OR) 2.92; $p<0.000)$ and in preterm infants $(\mathrm{OR} 1.98 ; p=0.005)$. Conclusions. CDR teams have been effective in improving identification of the causes of out-of-hospital deaths, as well as by identifying remediable factors critical to reducing child deaths further.

S Afr Med J 2016;106(9):895-889. DOI:10.7196/SAMJ.2016.v106i9.11234

In 2014, more than 40000 children died in South Africa (SA). ${ }^{[1]}$ Although under-5 mortality declined from 56 deaths per 1000 live births in 2009 to 41 per 1000 in $2013,{ }^{[2]}$ SA has not met the Millennium Development Goal to reduce under-5 mortality by twothirds. The under-5 child mortality rate in 2014 was 39 per 1000 , with most of these deaths preventable..$^{[1]}$ Importantly, neonatal and infant deaths accounted for a large proportion of under- 5 deaths.

Recent trends show that the reduction in under-5 deaths has plateaued. ${ }^{[3]}$ In order to reduce child mortality further to meet the sustainable development goals, it is critical to understand causes of death and associated factors. Vital registration data are incomplete, with ill-defined causes for $16 \%$ of deaths. ${ }^{[3]}$ Initiatives such as the health and demographic surveillance sites and facility-based data from the Child Healthcare Problem Identification Programme (Child PIP) provide a better understanding of causes of death and modifiable factors, particularly for preventable child deaths. ${ }^{[4]}$ Child PIP addresses some of the gaps by auditing child deaths in hospital and identifying modifiable causes in order to strengthen the health system at hospital, clinic and community levels. ${ }^{[5]}$ However, this fails to address the majority (55\%) of child deaths, which occur outside health facilities.

The first national child homicide study by the South African Medical Research Council (MRC) and the University of Cape Town sheds some light on deaths that occur outside facilities by drawing on mortuary and police data. ${ }^{[6]}$ This study estimated that 1018 children died as a result of homicide in 2009 , with a large proportion (44.6\%) of these deaths due to abuse and neglect. The study highlighted the fact that child murders were poorly investigated by the police and that a lack of co-ordination between health, police and social services compromised the management of child abuse deaths. ${ }^{[7]}$

Many high-income countries use standardised child death review (CDR) processes that view each death as a sentinel event from which lessons can be derived to improve the health and child protection systems. ${ }^{[8]}$ A Lancet series on child deaths in high-income countries $^{[8]}$ highlighted the efficacy of the multidisciplinary CDR process in improving accuracy in the reporting of causes of death and the contexts in which child deaths occur. At the core of the CDR process is the multidisciplinary team, comprising representatives from law enforcement, social services, health, forensic pathology and prosecution services who meet retrospectively to share case-specific information and review the circumstances of child deaths. ${ }^{[9,10]}$ The aim is to gather information about all factors contributing to a child's death, to systematically identify modifiable or remediable factors. ${ }^{[8]} \mathrm{CDR}$ teams have been shown to be effective in improving the identification of child deaths due to maltreatment, identifying modifiable causes of death, and using these findings to strengthen policy and service provision. ${ }^{[9]}$ 


\section{Objectives}

Based on the gaps identified by the MRC child homicide study and a review of international practices to manage child deaths, CDR teams were implemented and tested at two pilot sites in SA. The objective was to test the effectiveness of the teams in strengthening response systems and preventing child deaths in the local setting. This article describes the pattern of deaths reviewed and how the data can strengthen the current health and child protection system to improve the wellbeing of children.

\section{Methods}

The pilot was established at two sites for the period January - December 2014. Salt River (Western Cape) and Phoenix (KwaZulu-Natal) mortuaries were purposefully selected because of an interest by the forensic pathologists, the different sizes of the mortuaries (based on the number of bodies examined) and the diversity of the catchment districts. Phoenix mortuary, classified as M5, is based in Durban North with its area including the large informal settlements of KwaMashu and Inanda as well as the outlying rural areas of Ndwedwe and Ntuzuma. Salt River mortuary is an M6 mortuary that serves the suburbs, townships and informal settlements of Cape Town with catchment extending from Atlantis to Kommetjie, and from Camps Bay to Mitchell's Plain. (Designated facilities in the Forensic Pathology Service (mortuaries) are classified nationally according to their caseload per annum, M5 having a caseload of 1500 1999 bodies per annum and M6 $>2000$ bodies per annum.)

\section{The CDR concept}

The pilot was initiated by the Children's Institute, University of Cape Town, to foster an intersectoral collaborative approach to gather data systematically for each child death presenting to a medicolegal laboratory (mortuary). At the core of the process is the multidisciplinary team with representatives from law enforcement, social services, health, forensic pathology and prosecution services who meet retrospectively to share case-specific information and review the circumstances of child deaths. ${ }^{[9,10]} \mathrm{CDR}$ teams have been in operation in high-income countries for the past two decades, and to our knowledge this was the first attempt to test their feasibility in a low- or middle-income country.

CDR teams met monthly to review all child deaths (birth to 17 years of age) retrospectively, with a rapid, standardised response to the investigation, particularly for sudden, unexpected deaths. A standardised data collection form captured demographics, medical history and causeof-death data. The monthly review followed a standardised approach, with the forensic pathologist leading the discussion and all team members undertaking a confidentiality agreement. The review focused on identifying the events that led to the death based on the medical history and police investigation, identified additional information required, and established whether the death was preventable by considering potential modifiable or remediable factors.

\section{Definitions}

This study used the United Nations Convention on the Rights of a Child definition of a child as a person aged $<18$ years. We defined a neonate as a newborn aged $<28$ days and an infant as aged $<365$ days but out of the neonatal period.

The Inquests $\mathrm{Act}^{[11]}$ provides that a postmortem examination be performed to determine the cause of any death deemed not to be from natural causes and to establish who is responsible for the death. Unnatural deaths are defined in the Regulations to the National Health Act regarding the rendering of Forensic Pathology Service ${ }^{[12]}$ and include deaths from external causes and sudden, unexpected and unexplained deaths.

We defined fatal child abuse and neglect as a death due to physical abuse or neglect or negligence in the context of a relationship of responsibility and care, i.e. where the responsible person was a parent or caregiver; based on the Children's Act, ${ }^{[13]}$ neglect or negligence was defined as the omission of care resulting in the death of a child and often related to a natural cause of death. All cases of suspected rape and sexual assault were based on the postmortem findings and the police investigation, and were included as part of the definition of fatal child abuse. Live births were included in the study, based on postmortem examination, and a gestational age of 26 weeks was used as a marker for viability as defined by the Births and Deaths Registration Act. ${ }^{[14]}$

\section{Statistical analysis}

Data were analysed with Stata version 13 (StataCorp, USA). Descriptive statistics (means and proportions) were calculated and categorical variables were compared using Pearson's $\chi^{2}$ tests. A logistic regression analysis was used to identify factors associated with death. Mortality rates were calculated using 2014 live births and population estimates from the City of Cape Town and live birth and population estimates for the eThekwini district in KwaZulu-Natal as the denominator.

\section{Ethical considerations}

Ethical approval for the study was granted by the Ethics Committee of the Faculty of Health Sciences, University of Cape Town (HREC 396/2013).

\section{Results}

We reviewed 711 child deaths at the two sites for the pilot period. Salt River mortuary had 548 cases, three times the number of cases (163) reviewed at Phoenix. Table 1 shows a mortuary-specific child death rate of 8.1 deaths per 1000 live births for infants and 34 per 100000 for children aged $1-14$ years at Salt River mortuary and 2.0

Table 1. Description of infant and child death rates and non-natural death rates at the two pilot sites for 2014

\begin{tabular}{|c|c|c|c|c|}
\hline & $\begin{array}{l}\text { Mortuary-specific infant } \\
\text { death rate } \\
\text { (/1 } 000 \text { live births) }\end{array}$ & $\begin{array}{l}\text { Mortuary-specific child } \\
\text { death rate, } 1 \text { - } 4 \text { years } \\
(/ 100000)\end{array}$ & $\begin{array}{l}\text { Mortuary-specific child } \\
\text { death rate, } 5 \text { - } 14 \text { years } \\
(/ 100000)\end{array}$ & $\begin{array}{l}\text { Total mortuary-specific } \\
\text { child death rate, } 1 \text { - } 14 \text { years } \\
(/ 100000)\end{array}$ \\
\hline $\begin{array}{l}\text { Overall death rate, } \\
\text { Cape metro }\end{array}$ & 8.1 & 58.4 & 24.3 & 34.0 \\
\hline $\begin{array}{l}\text { Overall death rate, } \\
\text { northern eThekwini }\end{array}$ & 2.0 & 34.3 & 19.9 & 24.5 \\
\hline $\begin{array}{l}\text { Non-natural death rate, } \\
\text { Cape metro }\end{array}$ & 0.7 & 30.7 & 20.0 & 23.0 \\
\hline $\begin{array}{l}\text { Non-natural death rate, } \\
\text { northern eThekwini }\end{array}$ & 0.7 & 28.0 & 17.0 & 17.9 \\
\hline
\end{tabular}




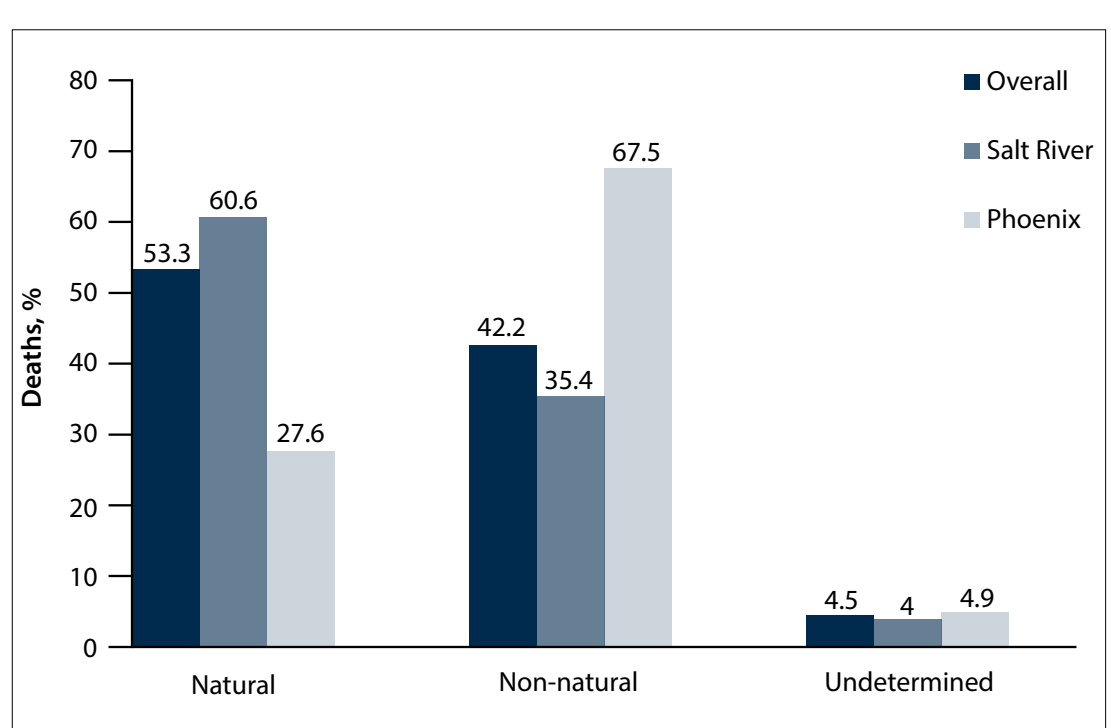

Fig. 1. Proportions of natural, non-natural and undetermined deaths at Salt River and Phoenix mortuaries.

Table 2. Characteristics of deaths by age category

\begin{tabular}{|c|c|c|c|c|c|}
\hline Characteristic & $\begin{array}{l}<1 \text { year } \\
(n=374), \%\end{array}$ & $\begin{array}{l}1 \text { - } 4 \text { years } \\
(n=105), \%\end{array}$ & $\begin{array}{l}5-14 \text { years } \\
(n=120), \%\end{array}$ & $\begin{array}{l}15-17 \text { years } \\
(n=108), \%\end{array}$ & $\begin{array}{l}\text { Total } \\
(N=707), \%\end{array}$ \\
\hline \multicolumn{6}{|l|}{ Manner of death } \\
\hline Natural & 83.7 & 37.1 & 15.0 & 6.4 & 53.3 \\
\hline Non-natural & 10.4 & 59.1 & 81.7 & 91.7 & 42.2 \\
\hline Undetermined & 5.9 & 3.8 & 3.3 & 1.9 & 4.5 \\
\hline \multicolumn{6}{|l|}{ Cause of death } \\
\hline Congenital & 3.2 & 1.0 & 0.8 & 0.0 & 2.0 \\
\hline Diarrhoea & 9.6 & 8.7 & 1.7 & 0.0 & 6.6 \\
\hline Lower RTI & 51.6 & 18.3 & 3.3 & 0.9 & 30.8 \\
\hline Stillbirth & 10.4 & 0.0 & 0.0 & 0.0 & 5.5 \\
\hline Other natural & 6.4 & 8.7 & 7.5 & 4.6 & 6.6 \\
\hline Burns & 0.8 & 14.4 & 7.5 & 0.9 & 4.0 \\
\hline Drowning & 1.1 & 5.8 & 5.0 & 1.9 & 2.5 \\
\hline RTA & 0.3 & 22.1 & 40.0 & 15.7 & 12.3 \\
\hline Homicide & 7.1 & 6.7 & 14.2 & 52.8 & 15.5 \\
\hline Suicide & 0.0 & 0.0 & 6.7 & 12.0 & 3.0 \\
\hline Other injury & 2.9 & 8.7 & 5.8 & 5.6 & 4.7 \\
\hline Undetermined & 5.6 & 1.9 & 2.5 & 1.9 & 4.0 \\
\hline \multicolumn{6}{|l|}{ Scene of death } \\
\hline Home & 68.9 & 51.9 & 27.5 & 23.2 & 52.4 \\
\hline Other home & 2.9 & 1.9 & 3.3 & 4.6 & 3.1 \\
\hline Public space & 10.4 & 26.0 & 54.2 & 58.3 & 27.4 \\
\hline Hospital/clinic & 17.3 & 20.2 & 11.7 & 13.0 & 16.1 \\
\hline Place unknown & 0.5 & 0.0 & 3.3 & 0.9 & 1.0 \\
\hline \multicolumn{6}{|l|}{$\begin{array}{l}\text { Death related to } \\
\text { child abuse and } \\
\text { neglect }\end{array}$} \\
\hline Yes & 13.0 & 13.5 & 9.2 & 5.6 & 11.3 \\
\hline No & 87.0 & 86.5 & 90.8 & 94.4 & 88.7 \\
\hline
\end{tabular}

deaths per 1000 live births for infants and 24.5 per 100000 for children aged $1-14$ years at Phoenix mortuary.

Fig. 1 shows that Salt River mortuary saw significantly more natural deaths $(60.6 \%)$ than Phoenix mortuary (27.6\%). The proportion of deaths with an undetermined cause was similar for both sites.

Table 2 shows the combined pattern of child mortality by age category. Overall, just over half $(53.3 \%)$ were natural deaths, compared with $42.2 \%$ non-natural deaths and $4.5 \%$ from undetermined causes. Of the 374 infant deaths reviewed, most (83.7\%) were due to natural causes. The proportion of natural deaths decreased as age increased, accounting for only $6.4 \%$ of deaths of 15 17 -year-olds. The opposite was found with non-natural deaths, which increased sharply from $59.1 \%$ in the 1-4-year age group to $91.7 \%$ in the $15-17$-year age group. Overall, children were more likely to die at home than in hospital (52.4\%), infants in particular (68.9\%). Children aged $>14$ years were more likely $(58.3 \%)$ to die in public spaces than younger children (10.4\%). Less than one in five child deaths reviewed (16.1\%) were in-hospital deaths, with the highest proportion $(20.2 \%)$ of in-hospital deaths in the 1 - 4-year age group.

Overall, the leading cause of death in children referred to the mortuaries was respiratory tract infection (RTI), resulting in nearly a third of deaths $(30.8 \%)$ and accounting for more than half $(51.6 \%)$ of deaths in children aged $<1$ year. Homicide was the second most common cause and spanned all age groups, with the highest burden in the 15 - 17-year age group (52.8\%). Suicide accounted for $12.0 \%$ of deaths in this older group. Road traffic accidents (RTAs) accounted for $12.3 \%$ of all deaths and peaked $(40.0 \%)$ in the 5 - 14-year age group. Child abuse and neglect accounted for $11.3 \%$ of deaths, with the highest proportion of deaths $(13.5 \%)$ in the $>5$-year age group.

Table 3 shows the pattern of deaths in the under-5 age group. RTI was the most common cause (41.9\%), followed by deliberate injury, abuse or neglect $(13.3 \%)$ and other perinatal causes (10.4\%). Similarly, RTI was the leading cause of death (58.2\%) in the 1-11-month age group, followed by deaths from diarrhoea (12.9\%) and from deliberate injuries, abuse and neglect (10.3\%). In addition, 1 in 5 children aged 1 4 years died as a result of an RTA.

Table 4 shows the factors associated with RTI deaths in infants. A death from a lower RTI was most likely after the neonatal period (odds ratio $(\mathrm{OR}) 2.92 ; p<0.000)$ and in preterm infants (OR 1.87; $p=0.009$ ). Infants who 


\begin{tabular}{|c|c|c|c|c|}
\hline Cause of death & $\begin{array}{l}0-28 \text { days } \\
(n=113), \%\end{array}$ & $\begin{array}{l}1 \text { - } 11 \text { months } \\
(n=263), \%\end{array}$ & $\begin{array}{l}1 \text { - } 4 \text { years } \\
(n=104), \%\end{array}$ & $\begin{array}{l}\text { Total }<5 \text { years } \\
(N=480), \%\end{array}$ \\
\hline \multicolumn{5}{|l|}{ Related natural causes } \\
\hline Congenital & 3.5 & 3.0 & 1.0 & 2.7 \\
\hline Diarrhoea & 0.0 & 12.9 & 7.7 & 8.8 \\
\hline Lower RTI & 27.4 & 58.2 & 16.4 & 41.9 \\
\hline Stillborn & 34.5 & 0.0 & 0.0 & 8.1 \\
\hline Other natural & 8.9 & 5.3 & 7.7 & 6.7 \\
\hline \multicolumn{5}{|l|}{ Related external causes } \\
\hline Child abuse and neglect & 19.5 & 10.3 & 14.4 & 13.3 \\
\hline RTA & 0.0 & 0.4 & 21.2 & 4.8 \\
\hline Other external ${ }^{*}$ & 2.7 & 5.7 & 30.7 & 10.4 \\
\hline Undetermined & 3.5 & 4.2 & 1.0 & 3.3 \\
\hline
\end{tabular}

Table 4. Factors associated with lower RTI during infancy

\begin{tabular}{llll}
\hline Variable & OR & $95 \%$ CI & $p$-value \\
\hline Age & & & \\
$\quad$ Neonate & 2.92 & $1.74-4.92$ & $<0.000$ \\
$\quad$ - 11 months & & & \\
Prematurity & Ref & - & 0.009 \\
$\quad$ Term & 1.87 & $1.17-2.99$ & \\
$\quad$ Preterm & & & 0.002 \\
Place of death & Ref & - & 0.122 \\
Hospital & 2.60 & $1.44-4.68$ & \\
Home & 0.46 & $0.17-1.23$ & 0.460 \\
$\quad$ Public space & & & 0.025 \\
Season & Ref & - & 0.137 \\
Summer & 1.29 & $0.66-2.53$ & \\
Autumn & 1.93 & $1.09-3.41$ & \\
$\quad$ Winter & 0.14 & $0.85-3.19$ & \\
$\quad$ Spring & & &
\end{tabular}

died unexpectedly at home were more likely to have died of an RTI than infants who died in hospital (OR 2.60; $p=0.002$ ), and infants were more likely to die in winter than in summer (OR 1.93; $p=0.025)$.

\section{Discussion}

This is the first CDR process for SA. The formation of multiagency teams to review child deaths at the two pilot sites provided invaluable insights into out-of-hospital deaths. This multidisciplinary enquiry enabled the co-ordinated investigation of deaths using evidence from medical records, autopsy reports, police and social services investigations. Each CDR team member played a specific role in the investigation, while the involvement of a child protection agency allowed for supporting families in crisis and protecting other children at risk in the family. We referred 52 cases for family support and recommended an investigation into the care of remaining children to a child protection agency; 33 referred cases were verified as neglect or omission of care.

At the core of the CDR process is an enquiry into each death by using a set of questions that investigate the web of factors that contributed to the child's death, particularly in sudden, unexpected and injury deaths. This requires an understanding of the deaths in the context of their environment, including factors at various levels: individual (biological and psychological); family, social, cultural, health and social welfare system issues that influence access to care; and the care the child received. ${ }^{[15]}$ In $13.2 \%$ of child deaths, caregivers abused substances and this may have affected their ability to care for the child adequately and seek timeous medical assistance. Where parents sought medical treatment, we found that health system failures potentially contributed to a further $11.2 \%$ of deaths. The pilot has shown that each child death provides a unique opportunity to understand contributing factors to ensure that appropriate prevention interventions are introduced.

\section{What is the pattern of deaths telling us?}

More than half (53.3\%) of the child deaths reviewed were due to natural causes. This pattern differed by mortuary, with Salt River admitting a larger proportion of natural deaths. Although eThekwini district in KwaZulu-Natal has a higher proportion of deaths in the health sector than the City of Cape Town ${ }^{[16]}$ this cannot fully explain the large difference. Despite the fact that medical practitioners should not be signing death notifications for sudden unexpected deaths, as per the National Health Act, our findings suggest that practices vary, with some more willing to complete death certification for out-of-hospital child deaths.

Homicide was the leading cause of injury deaths among children. The age pattern confirms the national child homicide study findings that teenage boys were most likely to die due to interpersonal male-on-male violence, and children aged $<5$ years to die in the home as a result of abuse and neglect. ${ }^{[6]}$ The pilot revealed that the majority of deaths of teenagers occurred in the context of peer conflict and gang-related violence, particularly in the Cape metropolitan area. Violence among young males is theorised to be deeply rooted in the context of inequality 
and youth unemployment in SA. ${ }^{[17]}$ In this context violence remains engendered as young men strive to attain violent forms of masculinity as the hegemonic ideal of what it means to be a 'real' man. ${ }^{[18]}$ Efforts to reduce youth violence require significant investment in adopting an approach that targets risk and promotes resilience during early childhood.

We found that child abuse deaths in the home contributed substantially to the burden of deaths in the under- 5 age group. Deaths due to severe physical abuse are most likely to be recognised as abuse deaths, while deaths related to omission of care, such as neglect, abandonment, drowning and poisoning, often remain undetected. ${ }^{[19]}$ The use of a CDR increased the accuracy of cause of death, and the team discussion facilitated in-depth enquiry to determine the circumstances surrounding each death. This resulted in an additional 33 cases of neglect or omission of care being identified. Although neglect did not necessarily cause the death, failure to seek timeous medical attention or lack of adequate supervision at the time of death contributed to it.

The early neonatal period was identified as a period of great risk, with 1 in 5 such deaths related to abandonment or being killed shortly after birth. This finding is supported by the national study on child homicides, which estimated that SA had one of the highest reported rates of neonaticide, at 19.6 per 100000 live births. ${ }^{[20]}$ Fatal child abuse and neglect should be conceptualised within the broader context of violence against children in SA and considered an endemic problem. ${ }^{[20]}$ This pilot highlights the urgent need to strengthen violence prevention efforts through multipronged approaches to reduce the risk of exposure to violence by early identification and prevention interventions and to enhance protective factors in families. ${ }^{[21]}$

Important insights into the association between RTI and deaths of preterm babies were made. We showed that RTI is associated with an increased risk of death of preterm babies during the post-neonatal period once they have been discharged home, and during winter. The state invests substantially in the care of preterm babies by up-scaling clinical care and introducing postnatal care packages to ensure that they survive the neonatal period. ${ }^{[22]}$ Nevertheless, we found that large numbers of preterm babies die shortly after hospital discharge, but these deaths are invisible in routine cause-of-death data. Our findings suggest a web of interrelated factors, with social circumstances, poor living conditions that intersect with limited support for new mothers, and quality of community-based services all contributing to preterm babies being vulnerable to death from preventable infections. This is supported by a review of child mortality in high-income settings, which concluded that a purely medical approach is inadequate and highlighted the need to consider social, behavioural and service delivery factors. ${ }^{[15]}$ Shifting the risk for preterm babies requires a multipronged approach with considerable investment in communitybased support at district level to sustain the gains from the early neonatal period.

\section{Study limitations}

We consider the determination of RTI in the infant cohort a possible limitation. The autopsy rate for infants varied between Phoenix (98.0\%) and Salt River (48.8\%). While there is no indication that the lack of standardised protocols across the two mortuaries led to under- or overdiagnosis of RTI deaths, this finding is consistent with international reports of pneumonia being the leading cause of death in children aged $<5$ years, particularly in Africa. ${ }^{[23]}$ The standard practice at Salt River in cases of natural death when no autopsy is performed is to arrive at the diagnosis on the basis of a full medical and social history, an Xmplar-dr chest X-ray (Lodox, SA) and full external examination. This practice is akin to the clinically diagnosed RTI in epidemiological surveys. ${ }^{[2]}$

\section{Conclusions}

The CDR pilot has provided valuable insights into out-of-hospital deaths. The review process, through in-depth case discussion using a social autopsy approach, examines the social factors contributing to child deaths in conjunction with medical causes to gain a better understanding of why and how children are dying. The pilot highlighted a dual problem: children aged $<5$ years are continuing to die from acquired natural causes (lower RTI), and there is a risk of fatal child abuse at home. The insights from this pilot clearly highlight the need to introduce and strengthen community-based interventions to assist in early identification of high-risk mothers through targeted support services and home-visitation programmes, particularly for preterm babies and high-risk mothers. There is a critical need to strengthen child protection services, with early intervention and prevention programmes essential to reduce the risk of fatal child abuse. Furthermore, interventions to strengthen families are vital to reduce child deaths but require investment in innovative multipronged programmes supported at the highest level to achieve global targets.

1. Statistics South Africa. Mortality and Causes of Death in South Africa, 2014: Findings from Death Notification. Pretoria: SSA, 2015.

2. Hall K, Meinties H. Demography of South Africa’s children. In: De Lannoy A, Swartz S, Lake L, Smith C eds. The South African Child Gauge 2015. Cape Town: Children's Institute, University of Cape Town, 2015. Nannan N, Dorrington R, Laubscher R, et al. Under-5 Mortality Statistics in South Africa: Shedding some Light on the Trends and Causes 1997 - 2007. Cape Town: South African Medical Research Souncil, 2012 .

Council, 2012.
McKerrow N, Mulaudzi M. Child mortality in South Africa: Using existing data. In: Padarath A, Fonn S, eds. South African Health Review. Durban: Health Systems Trust, 2010:59-72.

5. Stephen C, Bamford L. Saving Children 2010 - 2011. A Seventh Survey of Child Health Care in South Africa. Pretoria: South African Medical Research Council, Centres for Disease Control and Prevention, 2013.

6. Mathews S, Abrahams N, Jewkes R, Martin LJ, Lombard C. The epidemiology of child homicides in South Africa. Bull World Health Organ 2013;91(8):562-568. DOI:10.2471/BLT.12.117036

Mathews S, Abrahams N, Jewkes R, Martin LJ. Underreporting child abuse deaths: Experiences from a national study on child homicide. S Afr Med J 2013;103(3):132-133. DOI:10.7196/SAMJ.6724

8. Fraser J, Sidebotham P, Frederick J, Covington T, Mitchell EA. Learning from child death review in the USA, England, Australia, and New Zealand. Lancet 2014;384(9946):894-903. DOI:10.1016/S01406736(13)61089-2

9. Christian CW, Sege RD. Child fatality review. Pediatrics 2010;126(3):592-596. DOI:10.1542/ peds.2010-2006

10. Shanley JR, Risch EC, Bonner BL. U.S. child death review programs. Am J Prev Med 2010;39(6):522 528. DOI:10.1016/j.amepre.2010.08.010

11. Republic of South Africa. Inquests Act 58 of 1959. Pretoria: Government Gazette, 1959. http://www . Republic of South Africa. Inquests Act 58 of 1959. Pretoria: Gover
justice.gov.za/legislation/acts/1959-58.pdf (accessed 4 May 2016).

12. Republic of South Africa. Regulations to the National Health Act of 61 of 2003. Pretoria: Governmen Gazette, 2007. http://www.saflii.org/za/legis/consol_reg/nha61o2003rangnr636590.pdf (accessed 8 May 2016).

13. Republic of South Africa. Children’s Act 38 of 2005. Pretoria: Government Gazette, 2005. http:// discover.sabinet.co.za/document/GGD72002 (accessed 7 May 2016).

4. Republic of South Africa. Births and Deaths Registration Act 51 of 1992. Pretoria: Government Gazette, 1992. http://www.gov.za/sites/www.gov.za/files/a51_1992.pdf (accessed 17 May 2016).

15. Sidebotham P, Fraser J, Covington T, et al. Understanding why children die in high-income countries. Lancet 2014;384(9946):915-927. DOI:10.1016/S0140-6736(14)60581-X

16. Committee on Morbidity and Mortality in Children under 5 years. 2nd triennial report of the Committee on Morbidity and Mortality in Children under 5 years (COMMIC): 2014. Pretoria: COMMIC, 2014

17. Seedat M, van Niekerk A, Jewkes R, Suffla S, Ratele K. Violence and injuries in South Africa: Prioritising an agenda for prevention. Lancet 2009;374(9694):1011-1022. DOI:10.1016/S0140-6736(09)60948-X
an an agenda for prevention. Lancet 2009;374(9694):1011-1022. DOI:10.1016/S0140-6736(09)60948-X
Morrell R, Jewkes R, Lindegger G. Hegemonic masculinity/masculinities in South Africa: Culture, power, and gender politics. Men and Masculinities 2012;15(1):11-30. DOI:10.1177/1097184X12438001 9. Crume TL, DiGuiseppi C, Byers T, Sirotnak AP, Garrett CJ. Underascertainment of child maltreatment fatalities by death certificates, 1990-1998. Pediatrics 2002;110(2):e18.

20. Abrahams N, Mathews S, Martin LJ, Lombard C, Nannan N, Jewkes R. Gender differences in homicide of neonates, infants, and children under $5 \mathrm{y}$ in South Africa: Results from the cross-sectional 200 National Child Homicide Study. PLoS Med 2016;13(4):e1002003. DOI:10.1371/journal.pmed.1002003

21. Mathews S, Benvenuti P. Violence against children in South Africa: Developing a prevention agenda. In: Mathews S, Jamieson L, Lake L, Smith C, eds. South African Child Gauge 2014. Cape Town Children's Institute, University of Cape Town, 2014.

22. Velaphi S, Rhoda N. Reducing neonatal deaths in South Africa - are we there yet, and what can be done? S Afr J Child Health 2012;6(3):67-71. DOI:10.7196/SAJCH.493

23. Groen cause of death of children under five years in the Western Cape Province of South Africa. Trop Med Int Health 2016;21(1):114-121. DOI:10.1111/tmi.12624

24. Kovacs SD, Mullholland K, Bosch J, et al. Deconstructing the differences: A comparison of GBD 2010 and CHERG's approach to estimating the mortality burden of diarrhea, pneumonia, and their etiologies. BMC Infect Dis 2015;15:16. DOI:10.1186/s12879-014-0728-4

Accepted 11 July 2016 